\title{
SYNTHETIC ANALOGS OF THE ACTIVE SITES OF OXIDIZED AND REDUCED RUBREDOXIN
}

\author{
R. B. FRANKEL, G. C. PAPAEFTHYMIOU
}

Francis Bitter National Magnet Laboratory, Massachusetts Institute of Technology Cambridge, Massachusetts 02139, U. S. A.

and

\author{
R. W. LANE and R. H. HOLM
}

Chemistry Department Stanford University, Stanford, California 94305, U. S. A.

\begin{abstract}
Résumé. - L'anion $\left[\mathrm{Fe}\left(\left(\mathrm{SCH}_{2}\right)_{2} \mathrm{C}_{6} \mathrm{H}_{4}\right)_{2}\right]^{1-}$ contient l'unité de coordination $\mathrm{Fe}(\mathrm{III})-\mathrm{S}_{4}$ sans contrainte et de symétrie presque tétraédrique (ressemblant à l'unité de coordination $\mathrm{Fe}-\mathrm{S}_{4}$ qui se trouve dans la protéine de fer-soufre Rubredoxin)et présente le couplage rédox $\mathrm{Fe}$ (III)/Fe(II). Les paramètres Mössbauer à $77 \mathrm{~K}$ sont à déplacement isomérique $\delta=0,13 \mathrm{~mm} / \mathrm{s}$ (relatif au fer métallique) et éclatement quadrupolaire $\Delta E_{Q}=0,57 \mathrm{~mm} / \mathrm{s}$. L'application des champs magnétiques externes parallèles à la direction d'observation, à $4,2 \mathrm{~K}$, produit un champ de saturation hyperfin magnétique de $-380 \mathrm{kOe}$. Réduction au dianion $\left[\mathrm{Fe}\left(\left(\mathrm{SCH}_{2}\right)_{2} \mathrm{C}_{6} \mathrm{H}_{4}\right)_{2}\right]^{2-}$ change le déplacement isomérique à $\delta=0,61 \mathrm{~mm} / \mathrm{s}$ et l'éclatement quadrupolaire à $4,2 \mathrm{~K}$ à $\Delta E_{\mathrm{Q}}=3,34 \mathrm{~mm} / \mathrm{s}$. Nous avons déduit l'éclatement du niveau fondamental, $e\left(d_{z^{2}}, d_{x^{2}-y^{2}}\right), \Delta=900 \mathrm{~cm}^{-1}$, en considérant la dépendance de $\Delta E_{Q}$ par rapport à la température pour $1,4 \mathrm{~K}<T<295 \mathrm{~K}$. Des champs magnétiques jusqu'à 80 kOe révèlent le signe de $V_{z z}$ négatif indiquant que l'état fondamental est de symétrie $d_{z^{2}}$ et produisent une action réciproque hyperfine magnétique de signe négatif. Pour $\mathbf{H}_{0}=60 \mathrm{kOe}$, $\mathbf{H}_{\mathrm{hf}}=-128 \mathrm{kOe}$. $\left|\mathrm{H}_{\mathrm{h}}\right|$ s'accroît avec $\mathbf{H}_{0}$ démontrant qu'on n'est pas arrivé à saturation à $\mathbf{H}_{0}=80 \mathrm{kOe}$, impliquant d'un éclatement de champ zéro de l'état électronique fondamental de plusicurs $\mathrm{cm}^{-1}$. Ces résultats et mesures de moment magnétique pour les composés modèles libres sont comparables aux mesures de Rubredoxin à l'état ferreux et ferrique et impliquent que la description de Rubredoxin comme un « état entatic » n'est pas valide.
\end{abstract}

\begin{abstract}
The bischelate monoanion $\left[\mathrm{Fe}\left(\left(\mathrm{SCH}_{2}\right)_{2} \mathrm{C}_{6} \mathrm{H}_{4}\right)_{2}\right]^{1-}$ contains an unconstrained, near-tetrahedral $\mathrm{Fe}(\mathrm{III})-\mathrm{S}_{4}$ coordination unit (similar to the $\mathrm{Fe}_{4} \mathrm{~S}_{4}$ coordination unit occurring in rubredoxin proteins) and exhibits the $\mathrm{Fe}(\mathrm{III}) / \mathrm{Fe}(\mathrm{II})$ redox couple. Mössbauer parameters at $77 \mathrm{~K}$ are isomer shift $\delta=0.13 \mathrm{~mm} / \mathrm{s}$ (relative to iron metal) and electric quadrupole splitting $\Delta E_{\mathrm{Q}}=0.57 \mathrm{~mm} / \mathrm{s}$. Application of an external magnetic field parallel to the direction of observation at $4.2 \mathrm{~K}$ induces a saturation magnetic hyperfine field of $-380 \mathrm{kOe}$. Upon reduction to the dianion $\left[\mathrm{Fe}\left(\left(\mathrm{SCH}_{2}\right)_{2} \mathrm{C}_{6} \mathrm{H}_{4}\right)_{2}\right]^{2-}$ the isomer shift changes to $\delta=0.61 \mathrm{~mm} / \mathrm{s}$ and the quadrupole splitting at $4.2 \mathrm{~K}$ to $\Delta E_{\mathrm{Q}}=3.34 \mathrm{~mm} / \mathrm{s}$. From the temperature dependence of $\Delta E_{\mathrm{Q}}$ for $1.4 \mathrm{~K}<T<295 \mathrm{~K}$ we infer the splitting of the ground orbital doublet, $e\left(d_{z^{2}}, d_{x^{2}-y^{2}}\right)$, to be $\Delta \cong 900 \mathrm{~cm}^{-1}$. External magnetic fields up to $80 \mathrm{kOe}$ reveal the sign of $V_{z z}$ to be negative indicating that the ground orbital has $d_{z^{2}}$ symmetry and induce a magnetic hyperfine interaction of negative sign. For $\mathbf{H}_{0}=60 \mathrm{kOe}, \mathbf{H}_{\mathrm{hq}}=-128 \mathrm{kOe}$. $\left|\mathbf{H}_{\mathrm{hf}}\right|$ increases with increasing $\mathbf{H}_{0}$, showing that saturation has not been reached up to $\mathbf{H}_{0}=80 \mathrm{kOe}$, and implying a zero field splitting of several $\mathrm{cm}^{-1}$ of the electronic ground state. These results as well as magnetic moment measurements for the unconstrained model compounds are comparable to measurements in oxidized and reduced rubredoxin and imply that an «entatic state » description of rubredoxin is not valid.
\end{abstract}

1. Introduction. - Rubredoxin (Rd) is the simplest of the iron-sulfur proteins, containing a single iron atom per molecule, approximately tetrahedrally coordinated to four cysteinyl sulfur atoms [1]. It can undergo a reversible one-electron oxidation in which the iron is converted from ferrous to ferric. Unlike the case of heme-proteins where the coordination to the planar heme nitrogens determines the symmetry at the iron site to be primarily tetragonal [2] the symmetry in $\mathrm{Rd}$ is expected to be determined by the iron-ligand bond stereochemistry alone, provided that no severe constraints are imposed on the orientation of these bonds by the protein moiety. The observed symmetry is tetrahedral with a large rhombic distortion $[1,3]$. Departures from complete rhombicity $|E| D \mid<\frac{1}{3}$ observed in the electron paramagnetic spectra of oxidized Rd from Pseudomonas oleovorans obtained by Peisach et al. [3] were attributed by the authors to possible constraints that the protein superstructure may impose on the $\mathrm{Fe}-\mathrm{S}_{4}$ cluster. 
More significantly, X-ray diffraction studies of oxidized Rd from Clostridium pasteurianum by Jensen and coworkers [4] at the present $1.5 \AA$ stage of resolution demonstrate considerable deviations of the $\mathrm{Fe}-\mathrm{S}_{4}$ unit from a perfect tetrahedron. One of the $\mathrm{Fe}-\mathrm{S}$ bond lengths $(2.05 \AA \pm 0.03)$ is abnormally short and indeed falls outside the range of iron-sulfur bond lengths observed in any synthetic Fe(II, III)-SR complex [5]. The other three Fe-S bond lengths are nearly equal and fall within the $2.24-2.35 \AA$ range. This stereochemistry has been taken as evidence that the $\mathrm{Fe}-\mathrm{S}_{4}$ active site in $\mathrm{Rd}_{\mathrm{ox}}$ exists in a constrained state in accordance with the entatic state hypothesis of Vallee and Williams [6]. This hypothesis postulates that the conformation of the polypeptide chain imposes structural constraints on the active site of metalloenzymes resulting in a state of entasis or tension of unique physical and chemical properties with implications for the catalytic activity, redox potentials, and electron transfer kinetics of the proteins.

Recent extended X-ray absorption fine structure (EXAFS) studies of Rd using the high intensity $\mathrm{X}$-ray flux from synchrotron radiation show, however, that the four $\mathrm{Fe}-\mathrm{S}$ bond lengths are probably closer to being equal than the $X$-ray diffraction crystal structure of $\mathrm{Rd}_{o x}$ indicates. Studies on $\mathrm{Rd}_{\mathrm{ox}}$ from Peptococcus aerogenes by Shulman et al. [7] give an average $\mathrm{Fe}-\mathrm{S}$ bond distance of $2.24 \AA$ with a deviation of $0.1 \AA$. EXAFS measurements by Sayers et al. [8] on $C$. pasteurianum Rd yield an average $\mathrm{Fe}-\mathrm{S}$ bond length of $2.30 \AA \pm 0.04 \AA$ and a rms deviation about this average of $0.06 \AA \pm 0.004 \AA$.

Elucidation of the conflicting results on the structure of the $\mathrm{Fe}-\mathrm{S}_{4}$ cluster in $\mathrm{Rd}$ and a critical examination of the validity of the description of the $\mathrm{Fe}-\mathrm{S}_{4}$ complex in $\mathrm{Rd}$ as an entatic state may be approached by comparative studies of the protein and inorganic synthetic iron-sulfur compounds for which the local site symmetry is essentially unconstrained, and whose physical and electronic properties sufficiently closely approach those of the $\mathrm{Fe}-\mathrm{S}_{4}$ cluster in $\mathrm{Rd}$ that they can be considered suitable synthetic analogues $[5,9,10]$ of the protein itself. To this end we have carried out Mössbauer measurements on synthetic analogues of $\mathrm{Rd}_{\mathrm{ox}}$ and $\mathrm{Rd}_{\mathrm{red}}$ and compare the results with those of $\mathrm{Rd}_{\mathrm{ox}}$ and $\mathrm{Rd}_{\text {red }}$ available in the literature.

The bischelate monoanion $\left[\mathrm{Fe}\left(\left(\mathrm{SCH}_{2}\right)_{2} \mathrm{C}_{6} \mathrm{H}_{4}\right)_{2}\right]^{1-}$ (bis $\left(o\right.$-xylyl- $\alpha, \alpha^{\prime}$-dithiclato) ferrate (III) monoanion) contains an unconstrained, neartetrahedral $\mathrm{Fe}(\mathrm{III})-\mathrm{S}_{4}$ coordination unit and exhibits the $\mathrm{Fe}(\mathrm{III}) / \mathrm{Fe}$ (II) redox couple. Figure $1 a$ shows the X-ray diffraction structure obtained by Ibers [9] and figure $1 b$ gives the details of the structure around the iron atom. The X-ray structure [10] of the reduced compound $\left[\mathrm{Fe}\left(\left(\mathrm{SCH}_{2}\right)_{2} \mathrm{C}_{6} \mathrm{H}_{4}\right)_{2}\right]^{-2} \quad$ (bis $\left(o\right.$-xylyl- $\alpha, \alpha^{\prime}$-dithiolato) ferrate (II) dianion) is similar to that of the oxidized compound with an average increase of $0.1 \AA$ in $\mathrm{Fe}-\mathrm{S}$ bond distance upon reduction. These are the only synthetic analogues of $\mathrm{Rd}$ which have been isolated

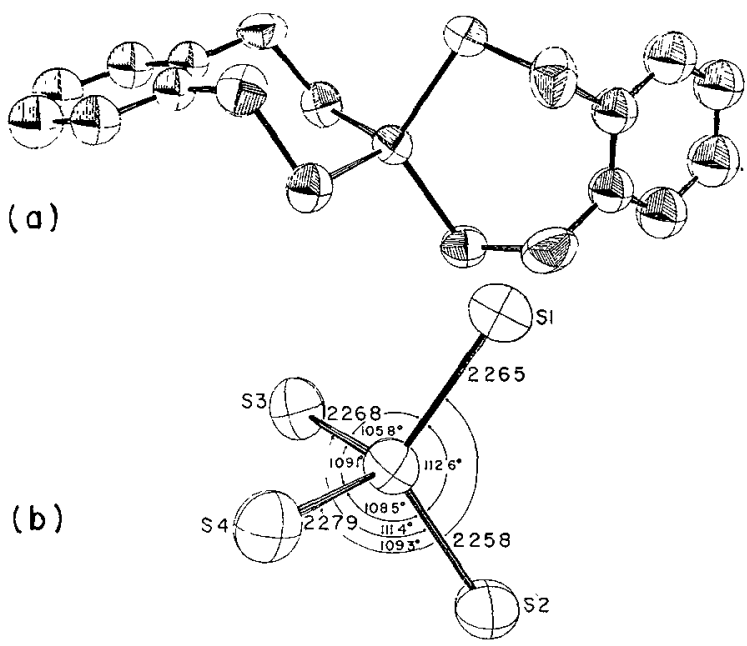

Fig. 1. - Structure of the $\left[\mathrm{Fe}\left(\left(\mathrm{SCH}_{2}\right)_{2} \mathrm{C}_{6} \mathrm{H}_{4}\right)_{2}\right]^{1-}$ anion as its $\mathrm{Et}_{4} \mathrm{~N}^{+}$salt : a) overall structure excluding $\mathrm{H}$ atoms ; b) dimensions of Fe(III)-S 4 group. (After Ref. [9].)

in both oxidation states with a common ligand structure. Thiolate sulfur coordination simulates cysteinate binding to iron in the native proteins.

2. Experimental. - Details on the synthesis, chemical and physical characterization and X-ray structure determination of the compounds are given in detail elsewhere [9, 10]. Mössbauer spectra were taken with a conventional constant acceleration spectrometer operated in the normalized mode. The spectrometer was equipped with a $\mathrm{Nb}-\mathrm{Sn}$ superconducting magnet and cryogenic equipment for measurements in longitudinal magnetic fields up to $85 \mathrm{kOe}$ and temperatures as low as $1.5 \mathrm{~K}$. The source, $\mathrm{Co}^{57}$ in $\mathrm{Rh}$, and absorber were maintained at the same temperature. All Mössbauer spectra were taken on crystalline or frozen solution samples with an average thickness of $3-5 \mathrm{mg} \mathrm{Fe} / \mathrm{cm}^{2}$, resulting on the average in $\sim 10 \%$ effects. Mössbauer parameters were obtained by least square fitting of the experimental data to Lorentzians, and all errors quoted are \pm 1 standard derivation obtained from the computer fits.

3. Results and discussion. - $\left[\mathrm{Fe}\left(\left(\mathrm{SCH}_{2}\right)_{2} \mathrm{C}_{6} \mathrm{H}_{4}\right)_{2}\right]^{1-}$ : Mössbauer spectra of $\left[\mathrm{Fe}\left(\left(\mathrm{SCH}_{2}\right)_{2} \mathrm{C}_{6} \mathrm{H}_{4}\right)_{2}\right]^{1-}$, the analog of $\mathrm{Rd}_{\mathrm{ox}}$, obtained as the tetraethyammonium salt were taken at room temperature, 77 and $4.2 \mathrm{~K}$. Samples in the crystalline phase and in dimethylformamide and dimethylformamide/dichloromethane $(3: 1 \vee / v)$ frozen solutions were studied. All spectra consist of a single quadrupole doublet with temperature-independent quadrupole splitting. Mössbauer parameters are summarized in table I together with results for $\mathrm{Rd}_{\mathrm{ox}}$ for comparison. The results are consistent with a high spin $\mathrm{Fe}(\mathrm{III})-\mathrm{S}_{4}$ coordination unit distorted from $T_{\mathrm{d}}$ symmetry. Mössbauer spectra at $4.2 \mathrm{~K}$ in the absence and presence of an applied 
TABLE I

\begin{tabular}{|c|c|c|c|c|c|c|}
\hline \multirow[b]{2}{*}{ Compound } & & \multirow{2}{*}{$\underset{V_{z z}}{\text { Sign of }}$} & \multirow[b]{2}{*}{$\Delta\left(\mathrm{cm}^{-1}\right)$} \\
\hline & $T(\mathrm{~K})$ & $\delta_{\mathrm{Fe}}(\mathrm{mm} / \mathrm{s})$ & $\Delta E_{\mathrm{Q}}(\mathrm{mm} / \mathrm{s})$ & $H_{\text {sat }}(\mathrm{kOe})$ & & \\
\hline \multirow[t]{3}{*}[\mathrm{Fe}((\mathrm{SCH}_{2})_{2}\mathrm{C}_{6}\mathrm{H}_{4})_{2}]{$^{-1}$} & 295 & $0.13 \pm 0.03$ & $0.57 \pm 0.05$ & & & \\
\hline & 77 & 0.13 & 0.57 & -380 & $(+)$ & \\
\hline & 4.2 & 0.13 & & & & \\
\hline \multirow{4}{*}[\mathrm{Fe}((\mathrm{SCH}_{2})_{2}\mathrm{C}_{6}\mathrm{H}_{4})_{2}]{$^{-2}$} & 295 & $0.61 \pm 0.03$ & $3.20 \pm 0.05$ & & & \\
\hline & 77 & 0.61 & 3.28 & & & \\
\hline & 4.2 & 0.61 & 3.34 & & $(-)$ & 900 \\
\hline & 1.4 & 0.61 & 3.32 & & & \\
\hline$\left[\mathrm{Fe}(\mathrm{SPh})_{4}\right]^{2-}\left(^{a}\right)$ & 77 & 0.64 & 3.24 & & & \\
\hline \multirow[t]{2}{*}{$\mathrm{Rd}_{\mathrm{ox}}$ (solution) } & 77 & $0.25\left(^{b}\right)$ & & $-370 \pm 3$ & & \\
\hline & 4.2 & $0.33\left(^{(}\right)$ & $0.5\left(^{(c)}\right.$ & & & \\
\hline \multirow[t]{3}{*}{$\operatorname{Rd}_{\mathrm{ox}}($ powder $)\left({ }^{d}\right)$} & 300 & $0.37 \pm 0.02$ & $0.74 \pm 0.02$ & & & \\
\hline & 77 & 0.37 & 0.78 & & & \\
\hline & 4.2 & 0.35 & $\begin{array}{l}\text { hyperfine } \\
\text { pattern }\end{array}$ & & & \\
\hline \multirow[t]{4}{*}{$\mathrm{Rd}_{\text {red }}$ (solution) } & 198 & $0.65\left(^{b}\right)$ & $3.10\left(^{b}\right)$ & & & \\
\hline & 77 & & $3.16\left(^{b}\right)$ & & & \\
\hline & 4.2 & & $3.16\left(^{b}\right)$ & -210 & $(-)$ & $>1000$ \\
\hline & 4.2 & $0.70\left(^{c}\right)$ & $3.25\left(^{c}\right)$ & & & \\
\hline \multirow[t]{3}{*}{$\operatorname{Rd}_{\text {red }}($ powder $)\left({ }^{d}\right)$} & 300 & $0.59 \pm 0.02$ & $3.24 \pm 0.04$ & & & \\
\hline & 77 & $0.60^{-}$ & 3.38 & & & 850 \\
\hline & 4.2 & 0.60 & 3.36 & & & \\
\hline
\end{tabular}

$\left({ }^{a}\right)$ Ref. [18] ; $\left(^{b}\right)$ Ref. [11]; (c) Ref. [13]; $\left(^{(a)}\right.$ Ref. [14].

field are shown in figure 2. The line shape at $77 \mathrm{~K}$ is asymmetric with the low velocity component broader and less intense than the high velocity component. At $4.2 \mathrm{~K}$ the lines are more nearly symmetric.

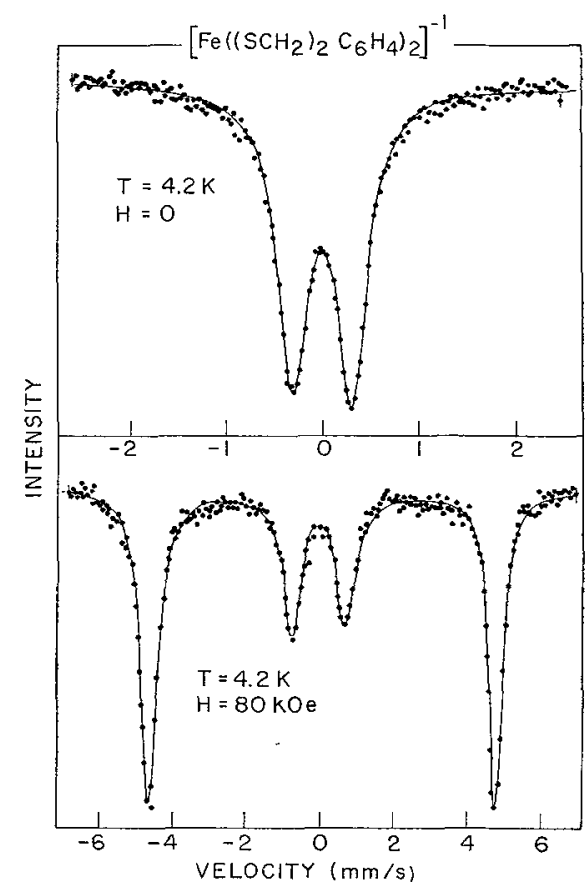

FIG. 2. - Mössbauer spectra of $\left(\mathrm{Et}_{4} \mathrm{~N}\right)\left[\mathrm{Fe}\left(\left(\mathrm{SCH}_{2}\right)_{2} \mathrm{C}_{6} \mathrm{H}_{4}\right)_{2}\right]$. The solid lines are theoretical least squares fits to the data assuming Lorentzian line shapes. The source is $57 \mathrm{Co}$ in $\mathrm{Rh}$, also at $4.2 \mathrm{~K}$
Application of longitudinal external magnetic fields up to $80 \mathrm{kOe}$ show that the sign of the principal component of the electric field gradient tensor, $V_{z z}$, is positive and that a magnetic hyperfine field is induced parallel to the applied field but in the opposite direction. The variation of the induced field with the magnitude of the applied field indicates that at $80 \mathrm{kOe}$ applied field saturation of the induced field has been reached with a saturation value $H_{\text {sat }}=-380 \mathrm{kOe}$. This is in good agreement with $H_{\text {sat }}=-370 \mathrm{kOe}$ obtained for $\mathrm{Rd}_{\text {ox }}$ [11] and implies similar bond covalency effects in the analogue and $\mathrm{Rd}_{\mathrm{ox}}$. These internal fields are reduced from the usual saturation value of about - $500 \mathrm{kOe}$ [12] found for $\mathrm{Fe}$ (III) with oxygen or nitrogen coordination, and presumably reflect the effects of spin depolarization and greater metal-ligand bond covalency. The absence of magnetic hyperfine structure at low temperatures in zero magnetic field and its presence in the $\mathrm{Rd}_{\mathrm{ox}}$ spectra reflect different electronic relaxation times for the two cases.

The near identity of Mössbauer spectra for $\left[\mathrm{Fe}\left(\left(\mathrm{SCH}_{2}\right)_{2} \mathrm{C}_{6} \mathrm{H}_{4}\right)_{2}\right]^{1-}$ observed in the crystalline state with those found in frozen solutions, including the magnetically perturbed spectrum in dimethylformamide-dichloromethane, implies that the solid and solution structures are the same. This indicates that no crystallographic constraints are imposed on the $\mathrm{Fe}_{-} \mathrm{S}_{4}$ structure. EPR spectra of

$$
\left[\mathrm{Fe}\left(\left(\mathrm{SCH}_{2}\right)_{2} \mathrm{C}_{6} \mathrm{H}_{4}\right)_{2}\right]^{1-}
$$


show a sharp $g=4.3$ signal [9] indicative of highspin rhombic Fe(III) but overall the spectra are more complicated than those of $\mathrm{Rd}_{\mathrm{ox}}$ and have not as yet been interpreted. This might be a result of exchange interactions between $\mathrm{Fe}-\mathrm{S}_{4}$ clusters which are absent in the protein due to their greater separation.

Magnetization measurements of

$$
\left[\mathrm{Fe}\left(\left(\mathrm{SCH}_{2}\right)_{2} \mathrm{C}_{6} \mathrm{H}_{4}\right)_{2}\right]^{1-}
$$

at $4.2 \mathrm{~K}$ are shown in figure 3 . The solid lines are theoretical assuming a Hamiltonian of the form

$$
\begin{aligned}
\mathbf{H}=D\left[S_{z}^{2}-\frac{1}{3} S(S\right. & +1)]+ \\
& +E\left(S_{x}^{2}-S_{y}^{2}\right)+2 \beta \mathbf{H}_{0} . \mathbf{S}
\end{aligned}
$$

with $E / D \sim \frac{1}{3}$ as indicated by the EPR results. At high field, the experimental values are reproduced

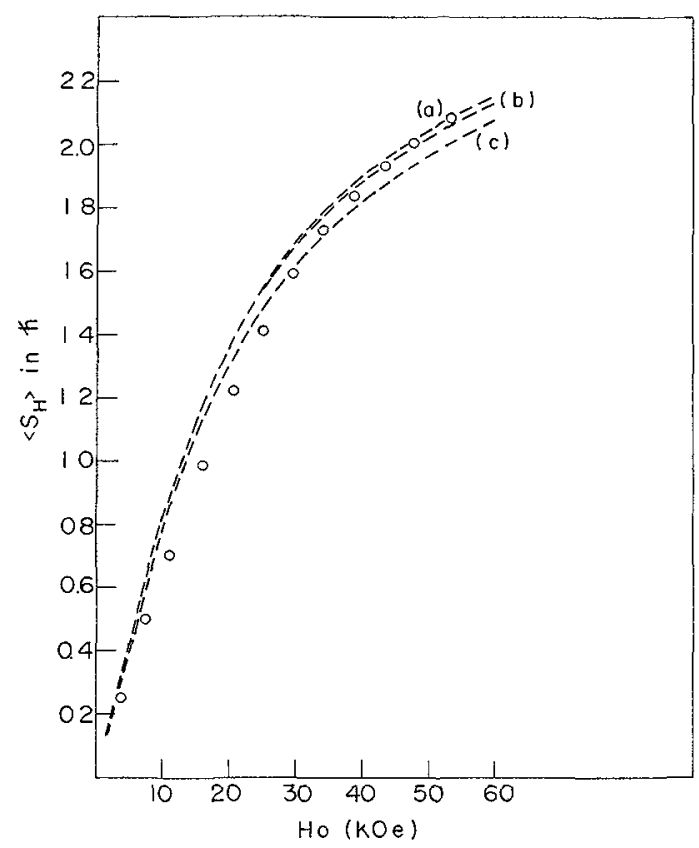

FIG. 3. - Magnetization data for $\left(\mathrm{Et}_{4} \mathrm{~N}\right)\left[\mathrm{Fe}\left(\left(\mathrm{SCH}_{2}\right)_{2} \mathrm{C}_{6} \mathrm{H}_{4}\right)_{2}\right]$ and theoretical lines for values of the parameters: a) $D=1.5 \mathrm{~cm}^{-1}$ and $E=0.5 \mathrm{~cm}^{-1}$ that best reproduce the higher field points, $b$ ) $D=1.76 \mathrm{~cm}^{-1}$ and $E=0.49 \mathrm{~cm}^{-1}$ for $P$. oleovorans $\mathrm{Rd}_{\text {ox }}$ and c) $D=1.89 \mathrm{~cm}^{-1}$ and $E=0.63 \mathrm{~cm}^{-1}$ for Clostridium acidi-urici $\mathrm{Rd}_{\mathrm{ox}}$ after $\mathrm{Ref}$. [3] are also shown. The spatial average over the unit sphere was carried out numerically for $\Delta \theta=10^{\circ}$ and $\Delta \varphi=10^{\circ}$

by $D=1.5 \mathrm{~cm}^{-1}$. Theoretical lines using the values of the parameters observed for $\mathrm{Rd}_{\mathrm{ox}}$ from Clostridium acidi-urici $\left(D=1.89 \mathrm{~cm}^{-1}, E=0.63 \mathrm{~cm}^{-1}\right)$ and $P$. oleovorans $\left(D=1.76 \mathrm{~cm}^{-1}, E=0.49 \mathrm{~cm}^{-1}\right)$ observed by Peisach et al. [3] are also shown. Similar values but with slightly smaller rhombicity were also obtained recently by Debrunner and Schultz [13] via Mössbauer spectroscopy. We observe that as the external field decreases, the induced spin along the applied field direction decreases faster than predicted by the spin Hamiltonian and is indicative of anti- parallel exchange coupling between iron-centers. This observation is consistent with the complexities of the EPR spectrum mentioned above and also the rapid electronic relaxation observed in the Mössbauer spectrum.

$\left[\mathrm{Fe}\left(\left(\mathrm{SCH}_{2}\right)_{2} \mathrm{C}_{6} \mathrm{H}_{4}\right)_{2}\right]^{2-}$ : Mössbauer spectra for crystalline samples of $\left[\mathrm{Fe}\left(\left(\mathrm{SCH}_{2}\right)_{2} \mathrm{C}_{6} \mathrm{H}_{4}\right)_{2}\right]^{2-}$ obtained as sodium (tetraphenylarsonium) salt were taken at $295,77,4.2 \mathrm{~K}$ and temperatures between 4.2 and $1.4 \mathrm{~K}$. All spectra consist of a single symmetric quadrupole doublet with a quadrupole splitting $\left(\Delta E_{\mathrm{Q}}\right)$ of the order of $3 \mathrm{~mm} / \mathrm{s}$ and isomer shift $(\delta)$ of $\sim 0.6 \mathrm{~mm} / \mathrm{s}$ indicative of high spin Fe(II). Spectral parameters are listed in table $I$ and spectra at $\mathbf{H}_{0}=0$ and various temperatures are shown in figure 4 .

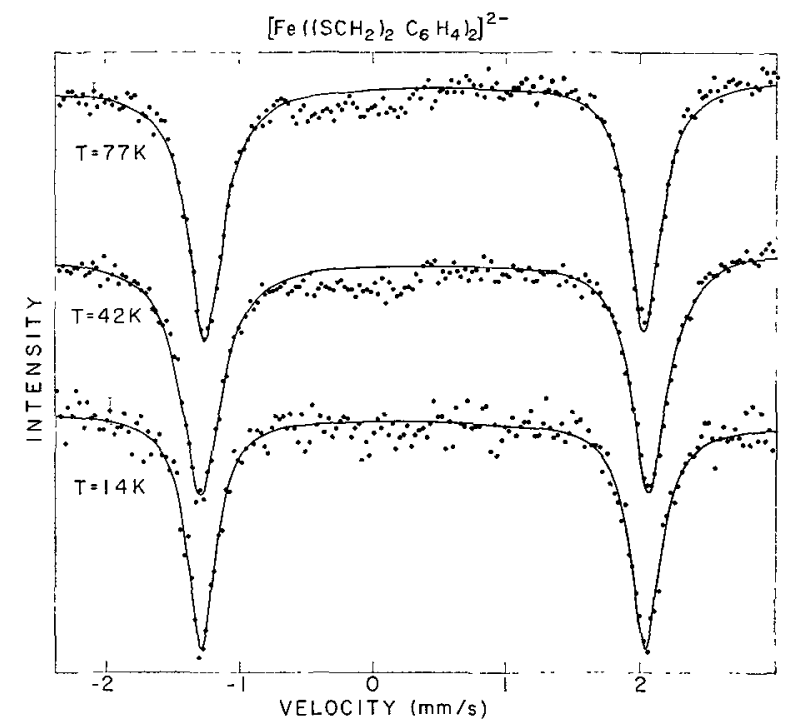

FIG. 4. - Mössbauer spectra of $\mathrm{Na}\left(\mathrm{Ph}_{4} \mathrm{As}\right)\left[\mathrm{Fe}\left(\left(\mathrm{SCH}_{2}\right)_{2} \mathrm{C}_{6} \mathrm{H}_{4}\right)_{2}\right]$

at various temperatures. The solid lines give least-squares fits of the experimental points to Lorentzian lines. The small broad feature centered about $0 \mathrm{~mm} / \mathrm{s}$ is presumably due to an $\mathrm{Fe}(\mathrm{III})$ impurity.

In a ligand field of $\mathrm{T}_{\mathrm{d}}$ symmetry the free ion ${ }^{5} \mathrm{D}$ term of $\mathrm{Fe}$ (II) is split into a lower ${ }^{5} \mathrm{E}\left(\mathrm{e}^{3} \mathrm{t}_{2}^{3}\right)$ and upper ${ }^{5} \mathrm{~T}_{2}\left(\mathrm{e}^{2} \mathrm{t}_{2}^{4}\right)$ state separated by $\sim 5000-6000 \mathrm{~cm}^{-1}$ in energy [10]. The large quadrupole splitting observed indicates that the ground state orbital degeneracy is lifted via a rhombic distortion of the tetrahedral point symmetry. From the small temperature dependence of $\Delta E_{\mathrm{Q}}$ observed over the temperature range $1.4-295 \mathrm{~K}$ (Table II), an estimate of the energy separation between the ground orbital to the next excited orbital state can be obtained by fitting the experimental data to an equation of the form $\Delta E_{\mathrm{Q}}(T)=\Delta E_{\mathrm{Q}}(0) \tanh (\Delta / 2 k T)$ expected for the thermal population of the two isolated orbital levels, $d_{z^{2}}$ and $d_{x^{2}-y^{2}}$, split by an energy $\Delta . \Delta E_{\mathrm{Q}}(0)$ is the quadrupole splitting at zero temperature when only the ground orbital state is populated and $\Delta E_{\mathrm{Q}}(T)$ is 
its value at temperature $T$. The above equation is correct within the approximation that any splittings due to the spin-orbit interaction are much smaller than $\Delta$ and the direct lattice contribution to the EFG is negligible. By using $\Delta E_{\mathrm{Q}}(0)=3.32 \mathrm{~mm} / \mathrm{s}$, the value observed at $1.4 \mathrm{~K}$, an estimate of $\Delta \cong 900 \mathrm{~cm}^{-1}$ is obtained. The temperature dependence observed by Rao et al. [11] for $\mathrm{Rd}_{\mathrm{red}}$ is somewhat smaller than that of $\left[\mathrm{Fe}\left(\left(\mathrm{SCH}_{2}\right)_{2} \mathrm{C}_{6} \mathrm{H}_{4}\right)_{2}\right]^{2-}$. The latter, however, is very similar to that of lyophilized reduced Rd observed by Phillips et al. [14] for which Eaton and Lovenberg [1] estimate $\Delta \cong 850 \mathrm{~cm}^{-1}$. Due to the small temperature variation observed and the experimental error associated with the values of $\Delta E_{\mathrm{O}}$, the above estimates of $\Delta$ are probably correct only within $\pm 100 \mathrm{~cm}^{-1}$.

To characterize further the ground state of the $\mathrm{Fe}(\mathrm{II})$ ion, Mössbauer spectra in longitudinal magnetic fields were obtained. As discussed by Collins [15] and Gabriel and Ruby [16] when the line width is taken into account, the superposition of the absorption lines arising from transitions between the magnetically perturbed nuclear levels in the presence of the randomly oriented EFG tensor in a powder absorber results in the splitting of the $\left|\frac{1}{2}, \pm \frac{1}{2}\right\rangle, \rightarrow\left|\frac{3}{2}, \pm \frac{3}{2}\right\rangle$ transition line into an apparent doublet and the $\left|\frac{1}{2}, \pm \frac{1}{2}\right\rangle$ line into an apparent triplet. The spectrum of $\left[\mathrm{Fe}\left(\left(\mathrm{SCH}_{2}\right)_{2} \mathrm{C}_{6} \mathrm{H}_{4}\right)_{2}\right]^{2-}$ in the presence of a magnetic field of $80 \mathrm{kOe}$ at $4.2 \mathrm{~K}$ is shown in figure 5 .

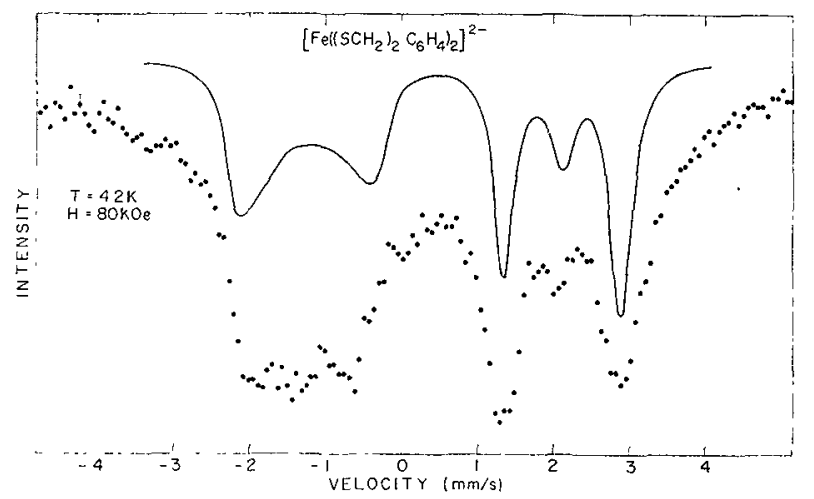

Fig. 5. - Mössbauer spectrum of

$$
\mathrm{Na}\left(\mathrm{Ph}_{4} \mathrm{As}\right)\left[\mathrm{Fe}\left(\left(\mathrm{SCH}_{2}\right)_{2} \mathrm{C}_{6} \mathrm{H}_{4}\right)_{2}\right]
$$

at $4.2 \mathrm{~K}$ in an external field of $80 \mathrm{kOe}$ applied parallel to the $\gamma$-ray direction. The solid line is theoretical for a powder sample with $\Delta E_{\mathrm{Q}}=3.32 \mathrm{~mm} / \mathrm{s}$ and an effective magnetic field of $63 \mathrm{kOe}$ with longitudinal configuration. The differences between the experimental data and calculated curve are due to anisotropy of the hyperfine interaction in the sample.

The low energy absorption line of the quadrupole doublet observed at $\mathbf{H}_{0}=0$ has been split into a doublet and the high energy absorption line into a triplet, indicating that the sign of the principal component of the EFG, $V_{z z}$, is negative. Similar spectra were obtained at lower values of the applied field as well as at higher absorber temperatures. The negative sign of $V_{z z}$ demonstrates that the ground state orbital of the $\mathrm{Fe}$ (II) ion has $d_{z^{2}}$ symmetry, as has previously been shown for $\mathrm{Rd}_{\mathrm{red}}$ [11]. The solid line in figure 5 is theoretical, assuming the field at the nucleus $\mathrm{H}_{\mathrm{n}}=63 \mathrm{kOe}$. The shape of the observed spectrum reflects anisotropy of the hyperfine interaction.

Figure 6 gives the energy level diagram within the $d^{6}$ electronic configuration for $\left[\mathrm{Fe}\left(\left(\mathrm{SCH}_{2}\right) \mathrm{C}_{6} \mathrm{H}_{4}\right)_{2}\right]^{2-}$.

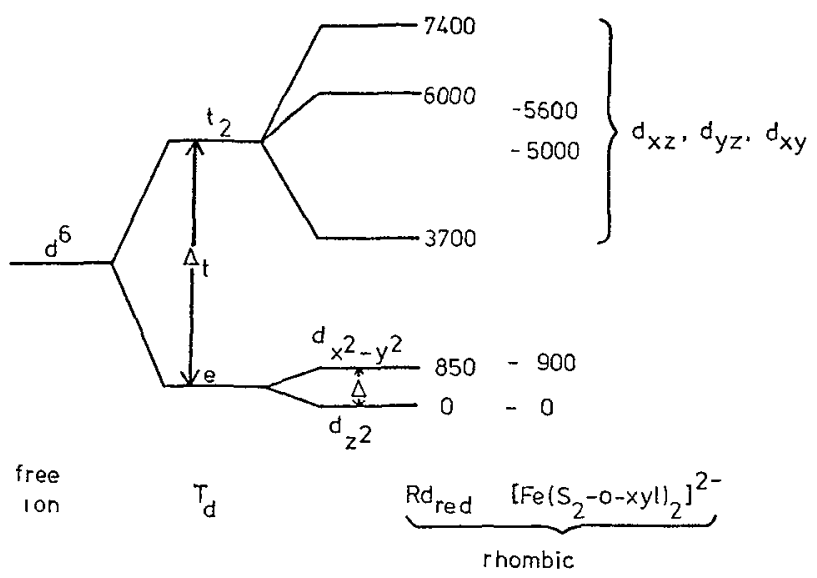

FIG. 6. - d-orbital energy level diagram for $F($ (II) in $\left[\mathrm{Fe}\left(\left(\mathrm{SCH}_{2}\right)_{2} \mathrm{C}_{6} \mathrm{H}_{4}\right)\right]^{2-}$ in distorted $T_{\mathrm{d}}$ symmetry. Orbital energies for $\mathbf{R d}_{\text {red }}$ are taken from Ref. [1].

The ground state symmetry and rhombic splitting $\Delta$ were determined by Mössbauer spectroscopy as described above, while the splittings of the upper state $t_{2}$ were inferred from electronic spectral measurements [10]. Here orbital separations are approximated with spectroscopic energy levels since all quintet states derived from the same term ${ }^{5} \mathrm{D}$ have the same mutual electron repulsion parameters. In the same diagram the corresponding energy levels for $\mathrm{Rd}_{\text {red }}$ [1] are also included for comparison. Although, the larger energy splittings of $t_{2}$ for the case of $\mathrm{Rd}_{\text {red }}$ indicates a probable greater distortion of the Fe- $\mathrm{S}_{4}$ symmetry in $\mathrm{Rd}$ the overall cubic splitting $\Delta_{\mathrm{t}}$ is of the same order for the two cases.

Comparisons of the observed Mössbauer spectra in the presence of external magnetic fields with computer generated spectra (Fig. 5) for an iron nucleus in the presence of a magnetic field in a randomly oriented EFG reveal that the observed field at the nucleus $\mathbf{H}_{\mathbf{n}}$ differs from the applied magnetic field $\mathbf{H}_{0}$, indicating the presence of a magnetic hyperfine interaction induced by the applied field. For $\mathbf{H}_{0}=60 \mathrm{kOe}$, $\left|\mathbf{H}_{n}\right|=68.5 \mathrm{kOe}$; for $\mathbf{H}_{0}=80 \mathrm{kOe},\left|\mathbf{H}_{n}\right|=63 \mathrm{kOe}$. Since $\mathbf{H}_{n}$ decreases as $\mathbf{H}_{0}$ increases from 60 to $80 \mathrm{kOe}$, we infer that the sign of $\mathbf{H}_{\mathrm{hf}}$ is negative. The 60 and 80 kOe spectral parameters yield $\mathbf{H}_{\mathrm{hf}}=-128$ and $-143 \mathrm{kOe}$, respectively. The parameters obtained at $1.4 \mathrm{~K}$ yield the same value of $\mathbf{H}_{\mathrm{hf}}$ as those obtained at $4.2 \mathrm{~K}$ for $\mathbf{H}_{0}=60$ and $80 \mathrm{kOe}$. The fact that $\left|\mathbf{H}_{\mathrm{hf}}\right|$ continues to increase as $\mathbf{H}_{0}$ increases from 60 to $80 \mathrm{kOe}$ implies a zero field splitting of the 
electronic ground state of the order of several degrees. The full saturation value of the magnetic hyperfine interaction constant would not be observed until $\mu H_{0}$ is large compared to the zero field splitting.

The magnetic hyperfine interactions induced by the applied field in the present case compare with those observed by Rao et al. [11] in $\mathrm{Rd}_{\text {red }}$ as follows. For $\mathbf{H}_{0}=60 \mathrm{kOe}$, they obtained $\mathbf{H}_{\mathrm{hf}}=-193 \mathrm{kOe}$ at temperatures between 4.2 and $1.3 \mathrm{~K}$. However, as discussed above, if there is a zero field splitting, this does not represent the full saturation value. If we assume comparable zero field splittings in the two cases, then the difference in the hyperfine interaction reflects a difference in the orbital character of the ground state. According to Marshall and Johnson [17] the magnetic hyperfine interaction arises from three principal contributions,

$$
\mathbf{H}_{\mathrm{hf}}=\mathbf{H}_{\mathrm{C}}+\mathbf{H}_{\mathrm{L}}+\mathbf{H}_{\mathrm{D}}
$$

where $\mathbf{H}_{\mathrm{C}}$ is the core polarization contribution arising from the Fermi contact interaction, $\mathbf{H}_{L}$ is the orbital moment contribution and $\mathbf{H}_{\mathrm{D}}$ is the field produced by the dipolar interaction with the spin moment of the iron atom. $\mathbf{H}_{D}$ is proportional to the EFG at the nucleus and is thus virtually the same in the two cases. It is also reasonable to assume $\mathbf{H}_{\mathrm{C}}$ to be comparable. This leaves $\mathbf{H}_{\mathrm{L}}$ to account for the difference, with a slightly large orbital contribution in the present case. This implies a larger value of $\Delta$ in $\mathrm{Rd}_{\text {red }}$, which is consistent with the smaller temperature variation of $\Delta E_{\mathrm{Q}}$ observed for $\mathrm{Rd}_{\text {red }}$.

In conclusion, the Mössbauer parameters $\delta, \Delta E_{\mathrm{Q}}$, $H_{\mathrm{hf}}$ collected in table I, together with the approximate values of the orbital doublet splitting $\Delta$, convincingly demonstrate that $\left[\mathrm{Fe}\left(\left(\mathrm{SCH}_{2}\right)_{2} \mathrm{C}_{6} \mathrm{H}_{4}\right)_{2}\right]^{2-}$ and C. pas- teurianum $\mathrm{Rd}_{\text {red }}$ have similar $\mathrm{Fe}(\mathrm{II})-\mathrm{S}_{4}$ geometries, ground state electronic structures, and $\mathrm{Fe}-\mathrm{S}$ bond covalency properties. This similarity doubtless extends to other Rd proteins such as, e. g., that from Ch. ethylica [11]. These results are also in agreement with the Mössbauer parameters of several tetrahedral $\mathrm{Fe}(\mathrm{II})-\mathrm{S}_{4}$ complexes recently measured by Kostikas et al. $[18]$ such as $\left[\mathrm{Fe}\left((\mathrm{SPh})_{4}\right]^{2-}\right.$, which is also included in table I. Their values at $77 \mathrm{~K}$ are entirely similar to those of $\left[\mathrm{Fe}\left(\left(\mathrm{SCH}_{2}\right)_{2} \mathrm{C}_{6} \mathrm{H}_{4}\right)_{2}\right]^{2-}$, whose isomer shift and quadrupole splitting in turn closely match those of C. pasteurianum $\mathrm{Rd}_{\mathrm{red}}$ [11].

Although the metal ion site symmetry in Rd proteins may be slightly different than is the case in the present analogues, the close degree of agreement observed suggests that the actual structural disparity between the unconstrained structural analogue

$$
\left[\mathrm{Fe}\left(\left(\mathrm{SCH}_{2}\right)_{2} \mathrm{C}_{6} \mathrm{H}_{4}\right)_{2}\right]^{1-}
$$

and $\mathrm{Rd}_{\mathrm{ox}}$ may not be as large as that suggested by a comparison of their X-ray diffraction crystal structures. Thus, the present results do not lend support to an entatic state description of the $\mathrm{Fe}-\mathrm{S}_{4}$ site in $\mathrm{Rd}_{\mathrm{ox}}$ or $\mathrm{Rd}_{\mathrm{red}}$. As mentioned in the introduction, this is in accord with the results of EXAFS studies.

Acknowledgments. - This research was supported at the Departments of Chemistry, M. I. T. and Stanford University, by NIH Grants GM-19256, GM-22351 and GM-22352. The Francis Bitter National Magnet Laboratory is supported by the National Science Foundation. G. C. P. was partially supported by a NIH Biomedical Sciences Support Grant administered by M. I. T. The authors are grateful to Dr. S. Foner for taking the magnetization measurements.

\section{References}

[1] Eaton, W. A. and Lovenberg, W., in Iron-Sulfur Proteins, Ed. W. Lovenberg (Academic Press, N. Y.) 1973, Chap. 3. Vol. II.

[2] Weissbluth, M., Struct. Bonding (Berlin) 2 (1967) 1 ;

HoArd, J. L., in Porphyrins and Metalloporphyrins, Ed. K. M. Smith (Elsevier Publishing Co., Amsterdam) 1975, Chap. 8.

[3] Peisach, J., Blumberg, W. E., Lode, E. T., Coon, M. J., J. Biol. Chem. 246 (1971) 5877 ;

Blumberg, W. E. and Peisach, J., Ann. N. Y. Acad. Sci. 222 (1973) 539.

[4] JeNSEn, L. H., Ann. Rev. Biochem. 43 (1974) 461 ;

Watenpaugh, K. D., Sieker, L. C., Herriott, J. R., JENSEN, L. H., Acta Crystallogr. B 29 (1973) 943 ;

JENSEN, L. H., in Iron-Sulfur Proteins, Ed. W. Lovenberg (Academic Press, N. Y.) 1973, Chap. 4, vol. II.

[5] Holm, R. H. and Ibers, J. A., in Iron-Sulfur Proteins, Ed. W. Lovenberg (Academic Press, N. Y.) 1976, Chap. 7, vol. III.

[6] Vallee, B. L. and Willuams, R. J. P., Proc. Nat. Acad. Sci. U.S. 59 (1968) 498.

[7] Shulman, R. G., Eisenberger, P., Blumberg, W. E. and Stombaugh, N. A., Proc. Nat. Acad. Sci. U. S. 72 (1975) 4003.
[8] Sayers, D. E., Stern, E. A. and Herriott, J. R., J. Chem. Phys. 64 (1976) 427.

[9] Lane, R. W., Ibers, J. A., Frankel, R. B. and Holm, R. H., Proc. Nat. Acad. Sci. U. S. 72 (1975) 2868.

[10] Lane, R. W., Ibers, J. A., Frankel, R. B., Papaefthymiou, G. C. and Holm, R. H., J. Am. Chem. Soc., in press.

[11] Rao, K. K., Evans, M. C. W., Cammack, R., Hall, D. O., Thompson, C. L., JACKSON, P. J. and JoHNSON, C. E., Biochem. J. 129 (1972) 1063.

[12] Freeman, A. J. and Watson, R. E., in Treatise on Magnetism, Ed. H. Suhl and G. Rado (Academic Press, N. Y.) 1965 , p. 167, vol. II A.

[13] Debrunner, P. and Schulz, C., Mössbauer Effect Methodology, Ed. I. J. Gruverman (Plenum Press) 1976, vol. 10.

[14] Phillips, W. D., Poe, M., Weiher, J. F., McDonald, C. C. and LOVENBERG, W., Nature 227 (1970) 574.

[15] Collins, R. L., J. Chem. Phys. 42 (1965) 1072.

[16] Gabriel, R. J. and Ruby, S. L., Nucl. Instrum. Methods 36 (1965) 23.

[17] Marshall, W. and Johnson, C. E., J. Physique Radium 23 (1962) 733.

[18] Kostikas, A., Petrouleas, V., Simopoulos, A., CoucouVANIS, D. and Holah, D. G., Chem. Phys. Lett. 38 (1976) 582. 